$=3482)$ vs. rofecoxib $(\mathrm{n}=6290)$; and, $1.31(0.86,2.01)$ when comparing non-naproxen NSAIDs or placebo $(\mathrm{n}=6017)$ vs. rofecoxib $(\mathrm{n}=7675)$.

Conclusion (1) The risk of sustaining a thrombotic cardiovascular event was similar in patients treated with rofecoxib, placebo, or non-selective NSAIDs without sustained effects on platelet function and, (2) the risk of sustaining a thrombotic cardiovascular event was reduced in patients treated with naproxen compared to rofecoxib. This reduction in events on naproxen is likely due to its ability to maintain near complete inhibition of platelet function throughout its dosing interval.

\section{SAT0047 PURINE METABOLISM AND ANTIOXIDANT SYSTEM IN OSTEOARTHRITIS}

AB Zborovsky, MY Stazharov, VF Martemyanov, SA Bedina, EE Mozgovaya, TP Chernykh. Laboratory for Clinical Biochemistry, Research Institute for Clinical and Experimental Rheumatology, Volgograd, Russia

\subsection{6/annrheumdis-2001.422}

Background Till now there are few of information on a Purine metabolism (PM) and Antioxidant system (AS) condition of blood of osteoarthritis (OA) patients.

Objectives To study the enzymatic profile of PM and AS in blood of OA patients.

Methods The activities of Xanthine Oxidase (XO), Xanthine dehydrogenase (XDG), 5'-Nucleotidase (5'-NT), Adenosindesaminase (ADA), Guanindesaminase (Guanase), Superoxid-dismutase (SOD), Glutathion reductase (GP), the contents of Uric acid (UA) were measured with Spectrophotometer. XDG, ADA, SOD isoenzymes were examined with method of electrophoresis in agarose gel and obtained enzymograms were evaluated at Densitometry.

Results 44 patients with OA and 30 healthy controls (HC) were under observation. The mean age of patients $-53 \pm 2.6$ years. The mean duration of disease $-10.2 \pm 2.7$ years. We revealed the increase of XO, ADA, Guanasa, SOD, GP, GR activity, XDG2 , SOD-1 isoensymes, contents of UA in OA patients with synovitis in comparison with HC. The increase of XDG, SOD, GP activity, SOD-1 isoensymes were observed in OA patients without synovitis in comparison with $\mathrm{HC}$ and the decrease of UA, XDG-2 isoenzymes, also the increase of XDG, GP activity were revealed in comparison with $\mathrm{OA}$ patients with synovitis.

Conclusion PM and AS are essentially changed in OA. These changes depended on the clinical form of OA. The enzyme indices can be used for early activity of disease diagnostic and differentiation of OA clinical form.

\section{SAT0048 A NEW ACID ATTACK AND CATHEPSIN K MEDIATED OSTEOLYTIC MECHANISM RECOGNISED AROUND LOOSENING THR IMPLANTS}

YT Konttinen, M Takagi, J Mandelin, J Lassus, J Salo, S Santavirta. Orton Research Institute, Invalid Foundation, Helsinki, Finland

\subsection{6/annrheumdis-2001.423}

Background Normal bone remodelling and pathological bone destruction have been considered to be osteoclast-driven. Osteoclasts are able to attach to bare bone surface and produce an acidic subcellular compartment. This leads to acid dissolution of hydroxyapatite allowing osteoclast-derived cathepsin $\mathrm{K}$ to degrade the organic type I collagen-rich osteoid matrix.
Objectives We were interested to find out the $\mathrm{pH}$ prevailing in the interface membrane, which develops around aseptically loosening total hip replacement (THR) implants. Our hypothesis was, that this hypovascular tissue, containing activated macrophages and subjected to ischemia-reperfusion, with an avascular implant embedded in it, is acidic. This could lead to demineralization and degradation of the demineralized bone matrix by acidic endoproteinases.

Methods We used a special sting electrode for peroperative $\mathrm{pH}$ measurements during revision THR operations performed for loosening. This electrode was sterilised using hydrogen peroxide plasma produced in a vacuum chamber and an electrical field generated using radiowave frequencies. Demineralization was assessed using Villanueva bone mineral stain analysed using confocal laser scanning microscopy. mRNA was isolated from interface tissue and measured using a quantitative RT-PCR method. Finally, cathepsin $\mathrm{K}$ enzyme protein was stained using biotinstreptavidin-peroxidase method and a staining robot and in double staining using manual double immunofluorescence method.

Results The $\mathrm{pH}$ at the gluteus medius control measure point was $7.39 \pm 0.05$. The value recorded at the interface tissue facing the periprosthetic bone was $6.1 \pm 0.2$ ( $p<0.001$ ). Confocal laser scanning of the adjacent bone disclosed high proportions of non-/red $(\mathrm{p}<0.01)$ and low-mineralized/yellow ( $\mathrm{p}<0.01$ ) bone compared to mature, mineralized bone/green around well-fixed, but mechanically broken cups. Cathepsin $\mathrm{K}$ mRNA copy number per thousand beta-actin copies was 1875 \pm 302 in interface compared to $268 \pm 61$ in control samples ( $p$ $<0.001)$. Interface tissue contained many cathepsin $\mathrm{K}$ enzyme protein positive cells, more than $95 \%$ of them being mononuclear, TRAP-positive cells of the monocyte/macrophage lineage. Furthermore, extracts of periprosthetic tissues contained both the $42 \mathrm{kD}$ pro- and the $27 \mathrm{kD}$ activated-form of the cathepsin $\mathrm{K}$ enzyme, whereas control samples contained only the $42 \mathrm{kD}$ proenzyme.

Conclusion These observations suggest that the low $\mathrm{pH}$ prevailing in the interface around loosening THR implants leads to demineralization of the periprosthetic bone. Under these acidic conditions, cathepsin $\mathrm{K}$ mRNA and enzyme protein production are induced in mononuclear cells. These cells release cathepsin $\mathrm{K}$ to the extracellular space, where it undergoes acid-induced autocatalytic activation and degrades demineralized periprosthetic bone matrix. These observations have therapeutic implications, because cathepsin $\mathrm{K}$ inhibitors are being developed for the treatment of metabolic bone diseases like osteoporosis.

\section{SAT0049 ANTERIOR KNEE PAIN AND HYPERLAXITY}

OF Sendur, T Yildirim, G Gürer, A Aydeniz. Physical Therapy and Rehabilitation, A. Menderes University Hospital, Aydin, Turkey

10.1136/annrheumdis-2001.424

Background Patellar malalignment is one of the most important reason of anterior knee pain and is determined by $\mathrm{Q}$ angle measurement. $\mathrm{Q}$ angle is defined as the angle between quadriceps muscle and patellar tendon. It is approximately 13 degrees in male and 18 degrees in female.

Objectives The first aim of this study is to determine $Q$ angle differences in supine and upright position. The second aim is to evaluate $\mathrm{Q}$ angle differences in person who have hyperlaxity compared to healthy ones. 
Methods In this study,253 healthy person was evaluated according to hyperlaxity and $\mathrm{Q}$ angle degrees. The measurements of hyperlaxity was carried out by using Beighton scoring system. According to the scores 5 and over 20 cases, less than 520 cases and finally other 20 cases in whom the laxity score was 0 degree were accepted as a control group.

We use one way Annova method to compare $\mathrm{Q}$ angle degrees in supine and upright position.

TUKEY-HSD test was applied to show relation between hyperlaxity and $\mathrm{Q}$ angle.

Results Standing and supine position $\mathrm{Q}$ angle values were not found statistically significant. $(\mathrm{p}>0.05)$ However hyperlaxity more than 5 (According to Beighton score was found statistically significant compared to control group.

Conclusion In our study we concluded that;

- There is no difference between supine and upright position $\mathrm{Q}$ angle values

- There is significantly corelation between hyperlaxity and Q angle values

\section{REFERENCE}

1 Graham R. Regional and heritable bone and collagen diseases: Hypermobility syndrome. In: Dieppe PA, Klippel HJ, eds. Rheumatology. London: Mosby, 1998:8:51-2

\section{SAT0050 OSTEOARTHRITIS OF THE FINGERS. EVALUATION OF A 4 MONTHS TREATMENT WITH DIACEREIN (VERBORIL)}

${ }^{1} \mathrm{AE}$ Georgiadis, ${ }^{2} \mathrm{C}$ Berberidis, ${ }^{3}$ I Koulouris, ${ }^{2} \mathrm{~B}$ Tataridis, ${ }^{2} \mathrm{~A}$ Lagoudakis, ${ }^{2} \mathrm{P}$ Alexiou, ${ }^{3} \mathrm{E}$ Koutris, ${ }^{3} \mathrm{~B}$ Papadakos, ${ }^{3} \mathrm{X}$ Rifiotis, ${ }^{3} \mathrm{E}$ Lyritsis. ${ }^{1}$ Osteoarthritis Center; ${ }^{2}$ Osteoarthritis Center, Multicenter Trial, Thessaloniki, Greece; ${ }^{3}$ Osteoarthritis Center, Multicenter Trial, Athens

\subsection{6/annrheumdis-2001.425}

Background Diacerein (Verboril) is a symptomatic slow-acting drug for the treatment of Hip and/or Knee Osteoarthritis (OA). Although Osteoarthritis of the fingers (OAF) is a very common form of $\mathrm{OA}$ and according to the epidemiological studies affects the $60 \%$ of the population, clinical studies concerning its treatment are very rare.

Objectives In order to determine if Diacerein has a beneficial effect on the clinical symptoms of OAF, we performed a prospective open multicenter study involving 30 doctors (rheumatologists or orthopaedics) in 5 Greek towns.

Methods 477 righthand female patients $(\mathrm{MA}=57,4 \pm 8,9 \mathrm{yrs})$, suffering from OAF according to ACR criteria, were enrolled in this study. All patients received $100 \mathrm{mg} /$ day of Diacerein for 4 $\mathrm{ms}$ and if needed NSAIDs and/or simple analgesics. All patients were evaluated at inclusion and at the end of $4 \mathrm{~ms}$ : a) for the presence of inflammatory and/or mechanical pain, b) for the presence and duration of morning stiffness, c) with the functional index of Dreiser d) for the concomitant consumption of analgesics and/or NSAIDs. We have used the t-test and chi-test in our statistical analysis and a probability level of 0,05 was considered to be statistically significant.

Results 225 patients have completed till now the 4 ms treatment and the analysis of their results showed a statistically significant improovement in clinical data, especially in Dreiser functional index $(p<0,005)$ and in the presence of inflammatory symptoms $(\mathrm{p}<0,001)$. The concomitant consumption of NSAIDs and/or analgesics was significantly lower at the end of $4 \mathrm{~ms}(\mathrm{p}<$ $0,05)$.
The overall assessment of therapy was good and very good for the $68 \%$ of patients and for the $72 \%$ of doctors. The safety profile of the drug was very good throughout the study period. Conclusion These data suggest that Diacerein appears to be very useful in the treatment of Osteoarthritis of the fingers.

\section{REFERENCE}

1 Dreiser RL, et al. Rev Rheum 1995;62:129-139S

\section{SAT0051 COX-2 SPECIFIC INHIBITION WITH MK-0663 120 MG Q D. OVER 4 WEEKS DID NOT INCREASE FAECAL BLOOD LOSS: A CONTROLLED STUDY WITH PLACEBO AND IBUPROFEN 800 MG T.I.D}

${ }^{1} \mathrm{RH}$ Hunt, ${ }^{2} \mathrm{P}$ Callegari, ${ }^{3} \mathrm{~B}$ Bowen, ${ }^{1} \mathrm{C}$ James, ${ }^{1} \mathrm{~J}$ Marshall, ${ }^{2} \mathrm{E}$ Mortensen, ${ }^{2} \mathrm{~A}$ Cagliola, ${ }^{2} \mathrm{C} \mathrm{Yu},{ }^{2} \mathrm{H}$ Quan, ${ }^{2} \mathrm{~T}$ Simon. ${ }^{1}$ Division of Gastroenterology; ${ }^{2} \mathrm{Clinical}$ Research, Gastroenterology, Merck Research Laboratories, West Point, USA; ${ }^{3}$ Department of Radiology, McMaster University Medical Centre, Hamilton, Canada

\subsection{6/annrheumdis-2001.426}

Background Treatment with existing NSAIDs is associated with increased gastrointestinal microbleeding. We conducted a double-blind, single centre study in 62 healthy volunteers (age 1933 years) to test the hypothesis that faecal blood loss with MK0663 (a new highly selective COX-2 inhibitor with a selectivity ratio of $>100$ in human whole blood assay) would be equivalent to placebo and superior to ibuprofen.

Objectives To compare faecal blood loss in volunteers taking MK-0663, ibuprofen, or placebo.

Methods Subjects were injected with ${ }^{51} \mathrm{Cr}$ labelled red blood cells and daily faecal blood loss in collected stool was measured by a large sample counter. Subjects with normal faecal blood loss during a 1-week placebo baseline period were randomised to MK-0663 $120 \mathrm{mg}$ q.d., ibuprofen $800 \mathrm{mg}$ t.i.d. or placebo treatment for 28 days. The effects of MK-0663 and placebo were compared by a predefined similarity bound for determination of equivalence.

Results The mean daily faecal blood loss ( $\mathrm{mL} /$ day) over time is shown in the table below. MK-0663 (120 mg) was equivalent to placebo and caused less blood loss than ibuprofen. All treatments were generally well tolerated.

\begin{tabular}{|c|c|c|c|}
\hline & $\begin{array}{l}\text { Placebo } \\
(\mathrm{N}=21)\end{array}$ & $\begin{array}{l}\text { MK-0663 } 120 \mathrm{mg} \\
(\mathrm{N}=23)\end{array}$ & $\begin{array}{l}\text { Ibuprofen } 2400 \mathrm{mg} \\
(\mathrm{N}=18)\end{array}$ \\
\hline Baseline & $0.37(0.31,0.44)$ & $0.31(0.27,0.36)$ & $0.38(0.33,0.43)$ \\
\hline Week 1 & $0.47(0.41,0.54)$ & $0.50(0.44,0.57)$ & $1.86(1.28,2.71)$ \\
\hline Week 2 & $0.70(0.60,0.81)$ & $0.70(0.57,0.87)$ & $2.09(1.72,2.53)$ \\
\hline Week 3 & $0.86(0.75,0.98)$ & $0.88(0.76,1.03)$ & $2.58(2.05,3.24)$ \\
\hline Week 4 & $0.99(0.88,1.12)$ & $0.99(0.85,1.15)$ & $3.39(2.39,4.80)$ \\
\hline
\end{tabular}

Geometric Mean (95\% Confidence Interval) Daily Faecal Blood Loss in mL/Day.

Conclusion In this study, the highly selective COX-2 inhibitor, MK-0663, at a dose twice that maximally effective in osteoarthritis, was equivalent to placebo, whereas a therapeutic dose of ibuprofen significantly increased faecal blood loss. 